\title{
Role of multidetector computed tomography (MDCT) in evaluation of main and right portal vein branching patterns and its clinical significance
}

\author{
Hira Lal' ${ }^{1}$, Aparna Juneja ${ }^{2}$, Pragati verma ${ }^{3}$, Ashok Kumar ${ }^{4}$, Raghunandan Prasad ${ }^{5, *}$ \\ ${ }^{1}$ Additional Professor, ${ }^{2}$ Senior Resident, ${ }^{3}$ Junior Resident, ${ }^{5}$ Assistant Professor, Dept. of Radiodiagnosis, ${ }^{4}$ Associate Professor, \\ Dept. of Surgical Gastroenterology, Sanjay Gandhi Postgraduate Institute of Medical Sciences, Raebareli Road, Lucknow, Uttar \\ Pradesh, India
}

*Corresponding Author:

Email: coolraghu2001@gmail.com

Received: $23^{\text {rd }}$ February, 2018

Accepted: $09^{\text {th }}$ March, 2018

\begin{abstract}
:
Introduction: Knowledge of the normal portal vein anatomy and its variations is imperative for various hepatic interventional procedures and liver surgeries like during creation of transjugular intrahepatic portosystemic shunt (TIPS), partial hepatectomy and Liver transplantation.

Aims and Objective: The aim of our study was to determine and analyse the spectrum of variations in the main and right portal vein anatomy and their prevalence in Indian population using MDCT.

Materials and Methods: Triple phase abdomen CT of 688 patients done on a 64 slice MDCT scanner between February 2012 and March 2014, were retrospectively evaluated by two radiologists independently. Out of these, 500 patients met the inclusion criteria. Axial images of portal and venous phase along with the maximum-intensity-projection and volume rendered images were reviewed and branching patterns of main and right portal vein were recorded.

Results: Normal portal vein anatomy was present in 67\% of the patients. Main portal vein (MPV) variations were seen in $15.2 \%$ of the patients. The most common variant was Z-type pattern (7.6\%). Next common was trifurcation pattern (6.6\%). Right portal vein (RPV) variations were seen in $17.8 \%$ of patients and the most common pattern was early segmental branching (6.8\%). Other RPV branching variations were RPV trifurcation (3.6\%), RPV quadrification (3.6\%), and superior-inferior division (1.4\%). Miscellaneous branching variations of RPV were seen in $2.4 \%$ of all patients.

Conclusion: Variations in the main portal vein and right portal vein anatomy are quite common and can be clearly detected with MDCT.
\end{abstract}

Keywords: Portal vein branching, Portal vein MDCT, MPV variation, RPV variation.

\section{Introduction}

Recognition of the variant portal vein anatomy is very important prior to procedures like TIPS, portal vein embolization, segmental/lobar hepatic resection, and liver transplantation. CT scan and MRI are invaluable modalities in providing road map of portal vein anatomy and its branching variations before these procedures. ${ }^{1}$ Triple phase MDCT allows a detailed assessment of arterial, portal and hepatic venous anatomy and has eliminated the invasive CT portography and conventional angiography for this purposes. ${ }^{2,3}$

Various previous studies including few from India have shown a large number of variations in MPV and RPV anatomy ranging from $9-35 \%$., $^{2,9}$

This study was conducted to determine the prevalence and analyze the spectrum of branching patterns of the main and right portal vein in Indian population in view of their clinical importance during various interventional procedures and liver surgeries.

\section{Materials and Methods}

Triple phase abdomen CT data of 688 patients done on a 64-slice MDCT scanner (Brilliance, Philips, Netherlands) between February 2012 and March 2014 was retrospectively analyzed for main portal vein and right portal vein anatomy. Cases of all ages were included in the study. Cases in which the portal vein anatomy was distorted due to a mass lesion, previous surgery, thrombosis, or gross intrahepatic biliary dilatation were excluded. However, if the portal vein anatomy was clear despite biliary dilatation, such cases were included in the study. In fact, most of the cases in our study had some degree of biliary dilatation. The cases in which portal vein showed poor contrast opacification or motion blur were also excluded. Total 500 patients CT data was found suitable and included in the study. There were 319 males and 181 females, and mean age was $42 \pm 18$ years. The CT scan parameters are described in Table 1. 
Table 1: CT scan parameters

\begin{tabular}{|c|c|c|c|}
\hline Contrast & \multicolumn{3}{|c|}{ Parameters } \\
\hline Oral contrast & \multicolumn{3}{|c|}{$500 \mathrm{ml}$ water just before scanning } \\
\hline $\begin{array}{l}\text { IV contrast - iodine } \\
\text { concentration } \\
(\mathrm{mg} / \mathrm{ml})\end{array}$ & \multicolumn{3}{|c|}{370 (Ultravist, Bayer) } \\
\hline Volume (mL) & \multicolumn{3}{|l|}{$90-95$} \\
\hline Flow rate $(\mathrm{mL} / \mathrm{sec})$ & \multicolumn{3}{|l|}{4} \\
\hline $\begin{array}{ll}\text { Saline } & \text { flush } \\
\text { volume }(\mathrm{mL}) & \end{array}$ & \multicolumn{3}{|l|}{40} \\
\hline $\begin{array}{l}\text { Saline flow rate } \\
(\mathrm{mL} / \mathrm{sec})\end{array}$ & \multicolumn{3}{|l|}{4} \\
\hline $\begin{array}{l}\text { Acquisition } \\
\text { parameters }\end{array}$ & $\begin{array}{c}\text { Hepatic } \\
\text { arterial phase }\end{array}$ & $\begin{array}{c}\text { Portal } \\
\text { venous phase }\end{array}$ & $\begin{array}{c}\text { Hepatic } \\
\text { Venous phase }\end{array}$ \\
\hline Scan delay (sec) & $\begin{array}{c}\text { Trigger at } 150 \\
\text { HU in aorta } \\
\text { plus } 5 \mathrm{sec}\end{array}$ & $\begin{array}{l}20 \mathrm{sec} \text { post } \\
\text { trigger }\end{array}$ & $\begin{array}{l}45 \mathrm{sec} \text { post } \\
\text { trigger }\end{array}$ \\
\hline Tube voltage $(\mathrm{kVp})$ & 120 & 120 & 120 \\
\hline Tube load (mAs) & 245 & 250 & 250 \\
\hline $\begin{array}{ll}\text { Gantry } & \text { rotation } \\
\text { time }(\mathrm{sec}) & \\
\end{array}$ & 0.75 & 0.75 & 0.75 \\
\hline $\begin{array}{l}\text { Detector } \\
\text { configuration }(\mathrm{mm})\end{array}$ & $64 \times 0.625$ & $64 \times 0.625$ & $64 \times 0.625$ \\
\hline Pitch & 1.172 & 1.172 & 0.891 \\
\hline \multicolumn{4}{|l|}{$\begin{array}{l}\text { Reconstruction } \\
\text { parameter }\end{array}$} \\
\hline $\begin{array}{l}\text { Axial section width } \\
(\mathrm{mm})\end{array}$ & 1 & 2 & 2 \\
\hline $\begin{array}{l}\text { Recon increment } \\
(\mathrm{mm})\end{array}$ & 0.5 & 1 & 1 \\
\hline
\end{tabular}

Axial raw data was transferred to a Brilliance workstation (Philips, Netherland) where analysis of the portal venous anatomy was done by two radiologists independently. After evaluating the axial images, maximum-intensity-projection (MIP) and volumerendered (VR) images were reviewed in various planes. Portal and venous phase images were used for evaluation of the portal venous anatomy. All these variations were analyzed by two radiologists independently (each with 5 year experience) and in case of any discrepancy, the scan was discussed with the senior radiologist (with 12 year experience) and his decision was taken as final.

Variations of MPV and right portal vein (RPV) branching pattern were separately recorded. To avoid making this study complex left portal vein (LPV) branching pattern and its variations were not evaluated. Normally, the MPV divides into RPV and LPV. RPV further divides into right anterior portal vein (RAPV) which supplies segment V \& VIII, and right posterior portal vein (RPPV) which supplies segment VI \& VII. MPV variations were classified into trifurcation (Fig.1a and 1b), Z-type pattern (Fig.1c and 1d), quadrification (Fig. 2a \& b) and total ramification. In total ramification MPV gives a branch to each segment as it traverses through the liver, and there is no division of
MPV into right and left branches. If the common RAPV-LPV trunk was too small mimicking a trifurcation variant, the MIP and VR images were carefully evaluated as suggested by Hwang et al. ${ }^{10}$ When a triangular gap was formed between the RAPV and RPPV the case was classified as trifurcation, where as if a rectangular gap was formed it was classified into a Z-type variant. ${ }^{11}$

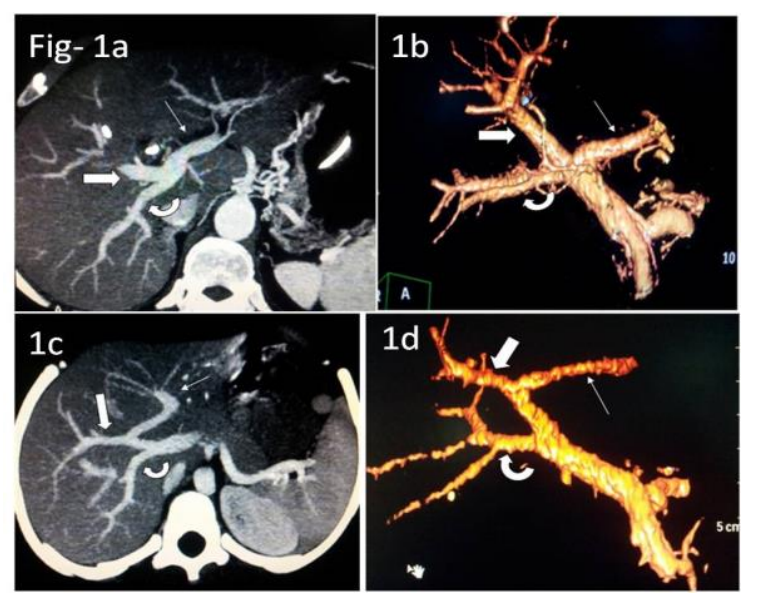

Fig 1: Axial Maximum-intensity-projection (MIP) image (Fig 1a) and volume rendered (VR) images (Fig 1b) showing the trifurcation pattern of MPV 
dividing into LPV (arrow), RAPV (block arrow), and RPPV (curved arrow). Axial MIP (Fig 1c) and VR images (Fig 1d) showing the Z-type variant of MPV, with RAPV (block arrow) arising from LPV (arrow) and RPPV (curved arrow) as continuation of MPV

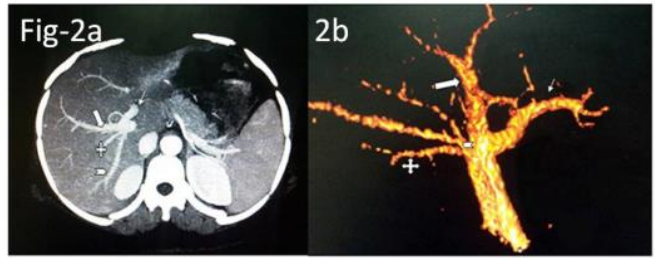

Fig 2: Axial MIP (Fig-2a) and VR images (Fig-2b) showing quadrification pattern of MPV giving LPV (arrow), RAPV (block arrow), segment VI (plus) and segment VII (chevron) branches.

The right portal vein variations were classified as early segmental branch, RPV trifurcation, RPV quadrification and RPV branching into superior and inferior divisions. In these cases MPV divided into right and left branches as usual but segmental right portal vein anatomy was different. In early segmental branching pattern a segmental branch (segment V/VI/VII/VIII) originated as the first major branch of RPV after which RPV supplied the other three segments (Fig. 3a, b, c \& 4a, b). In RPV quadrification pattern, RPV divided into four different branches at one point supplying the right lobe (Fig. 4c \& d). In RPV trifurcation pattern, RPV trifurcated into two segmental branches and a common branch supplying two other segments (Fig.5a \& b). In RPV superior and inferior division pattern, the RPV divided into a superior branch which supplied segments VII \& VIII and an inferior branch which supplied segment V \& VI (Fig. 5c).

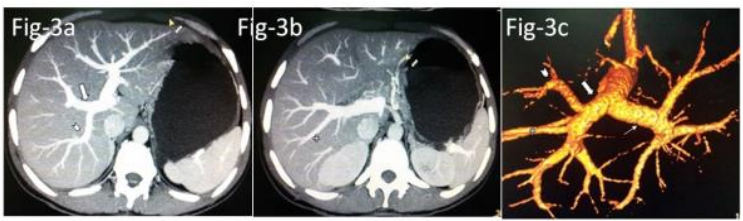

Fig 3: Axial MIP and VR images showing early segmental RPV branching. Fig-3a- Segment VII (chevron) branch arising as the first branch of RPV (block arrow). Fig-3b- Axial section at inferior level showing further branching of RPV into segment VI (plus) and RAPV. Fig-3c-VR image showing the early segmental branch type pattern. LPV (thin arrow)

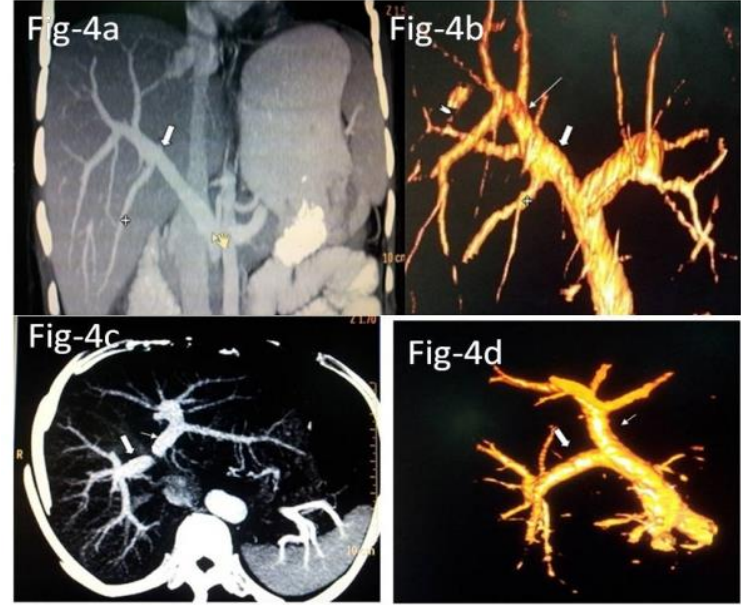

Fig 4: Contrast enhanced coronal MIP (Fig-4a)and VR image (Fig-4b) showing early segmental branching of RPV (block arrow) with segment VI (plus) arising as the first branch with further division of RPV into segment VII (chevron) and RAPV (arrow). (Cursor pointing at the main portal vein). Axial MIP (Fig-4c) and VR images (Fig-4d) in portal phase showing RPV (block arrow) branching into four different branches (LPV represented by arrow)
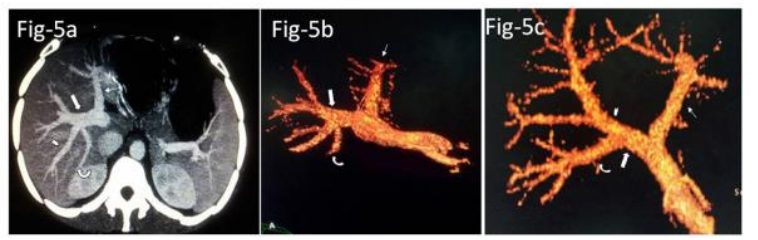

Fig 5: Axial MIP (5a) and VR images (5b) showing the RPV (block arrow) trifurcation into segment VI (curved arrow), VII (chevron) and RAPV (LPV is represented by arrow). Another VR image (5d) showing the superior and inferior branching pattern of RPV (block arrow) with superior division supplying segment VII and VIII superiorly (chevron) \& inferior division supplying segment $V$ and VI (curved arrow). (LPV is represented by arrow)

Any of the variation not fitting into these patterns was assigned a miscellaneous group. Any major portal venous branch crossing the Cantlie's line to supply segments of other lobe were also noted (Fig. $6 \mathrm{a} \& \mathrm{~b}$ ); however, minor branches $(<2 \mathrm{~mm})$ were not taken into account. 

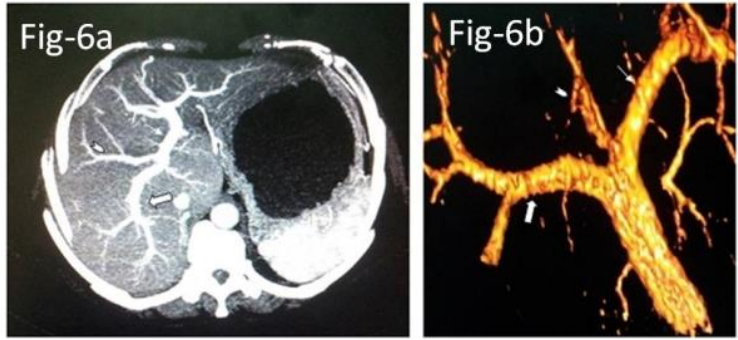

Fig 6: Axial MIP (6a) and VR images (6b) in a portal phase showing segment VIII branch (chevron) arising from LPV (arrow), RPV (block arrow) giving branches to segment V, VI, VII

\section{Results}

Out of the total 500 patients included in the study, $335(67 \%)$ had normal portal vein anatomy while variant anatomy was found in $165(33 \%)$.

Variant MPV anatomy was found in $76(15.2 \%)$ patients (Table 2).

Table 2: Main portal vein variations in 500 patients

\begin{tabular}{|c|c|}
\hline Variation & Number of patients (\%) \\
\hline Trifurcation & $33(6.6)$ \\
\hline Z-type branching & $38(7.6)$ \\
\hline Quadrification & $3(0.6)^{*}$ \\
\hline Total ramification & $0(0)$ \\
\hline Miscellaneous & $2(0.4)^{* *}$ \\
\hline \multicolumn{2}{|c|}{$\begin{array}{l}\text { *Quadrification pattern-LPV, RAPV, segment VI } \\
\text { and VII in two patients and LPV, segment VII, } \\
\text { segment VIII, and a common trunk for segment V } \\
\text { and VI } \\
\text { **MPV dividing into a RPV, LPV and a } \\
\text { segmental branch - segment VII in both patient }\end{array}$} \\
\hline
\end{tabular}

In few patients the RPV trunk was so small that it mimicked MPV trifurcation variant on axial and MIP images. However, in these cases VR images proved an effective tool to categorize the variation where even as short as $2-3 \mathrm{~mm}$ trunk was clearly visible.

RPV variations were found in $89(17.8 \%)$ patients (Table 3).

Table 3: Right portal vein (RPV) variations in $\mathbf{5 0 0}$ patients

\begin{tabular}{|l|c|}
\hline \multicolumn{1}{|c|}{ Variation } & $\begin{array}{c}\text { Number of patients } \\
(\%)\end{array}$ \\
\hline $\begin{array}{l}\text { Early segmental } \\
\text { branch }\end{array}$ & $34(6.8)$ \\
\hline RPV Trifurcation & $18(3.6)$ \\
\hline RPV quadrification* & $18(3.6)$ \\
\hline $\begin{array}{l}\text { Superior and Inferior } \\
\text { division }\end{array}$ & $7(0.4)$ \\
\hline \multicolumn{2}{|l|}{ Miscellaneous } \\
\hline *each branch supplied a different segment \\
\hline
\end{tabular}

Early segmental branching and RPV trifurcation patterns have been further subcategorized (Table 4).

Table 4: Subcategories of early segmental branching and RPV trifurcation patterns of Right portal vein

\begin{tabular}{|l|c|}
\hline \multicolumn{1}{|c|}{ Variation } & $\begin{array}{c}\text { Number of } \\
\text { patients (\%) }\end{array}$ \\
\hline Early segmental branch & \\
\hline $\begin{array}{l}\text { Seg.VII as first branch, RPV further } \\
\text { dividing into seg. VI and RAPV }\end{array}$ & $19(3.8 \%)$ \\
\hline $\begin{array}{l}\text { Seg.VI as first branch, RPV further } \\
\text { dividing into seg. VII and RAPV }\end{array}$ & $10(2 \%)$ \\
\hline $\begin{array}{l}\text { Seg.V as first branch and RPV } \\
\text { further dividing into seg. VI, VII, } \\
\text { VIII }\end{array}$ & $1(0.2 \%)$ \\
\hline Seg. VIII as first branch & $4(0.8 \%)$ \\
\hline RPV Trifurcation pattern & $13(2.6)$ \\
\hline Segment VI, VII and RAPV & $4(0.8)$ \\
\hline Segment V, VIII and RPPV & $1(0.2)$ \\
\hline $\begin{array}{l}\text { Segment VII, VIII and inferior } \\
\text { division }\end{array}$ & \\
\hline
\end{tabular}

Miscellaneous patterns of RPV variations were seen in $12(2.4 \%)$ patients. In $5(1 \%)$ patients, RPV gave branches to segment V, VI, and VII and segment VIII supply was derived from left portal vein. RAPV giving superior and inferior divisions which supplied segments VII, VIII and V, VI respectively and RPPV giving additional supply to segment VI and VII were seen in two patients. Additional supply of segment $\mathrm{V}$ from RPPV and segment VI from RAPV were seen in two patients. Such a variation is considered as a relative contraindication for right lobe harvesting. ${ }^{9}$

In one patient RPV supplied only the right posterior segments and the right anterior segments were supplied from left portal vein. We did not find any major branches crossing the Cantlie's line from right to left side in our study. However Segment VIII supply was derived from LPV in 5(1\%) patients.

\section{Discussion}

Branching variations of portal vein have huge surgical implications especially during liver transplant and various interventional procedures like portal vein embolization and during TIPS creations. ${ }^{12}$ These complex liver surgeries and interventions are now much more commonly performed than ever with development of better healthcare facilities and infrastructure, and knowing the exact portal vein anatomy is of paramount importance for these procedures. The branching variations can complicate the graft harvesting and anastomosis during liver transplant, which may lead to post transplant complications. Hence, accurate preoperative knowledge of vascular anatomy is essential. Detailed vascular evaluation is feasible with the present day MDCT scanners which have eliminated the 
invasive CT portography and conventional angiography for this purpose. MDCT angiography analyzes the vascular anatomy in great detail by providing high resolution image in any desired plane and 3dimensional reconstruction like MIP and VR images.

This study was done for the assessment of the branching pattern of MPV and RPV in the Indian population. As compared to the western data, the prevalence and types of branching patterns in our study are similar. The most common MPV variation in our study was the Z-type branching followed by trifurcation pattern. These results are somewhat similar to previous studies who have also reported Z-type and trifurcation as the most common MPV variants. ${ }^{2,11,13-15}$

Generally variation in RPV branching is not a contraindication for liver transplantation; but it may pose difficulty in cases of tumor resection and during creation of TIPS. In our study RPV variations were found to be slightly more common than variation in MPV branching. RPV branching variations have not been studied in much detail in previous studies. ${ }^{5,6}$

We noticed a new type of branching pattern in our study; RPV branching into superior and inferior divisions instead of RAPV and RPPV in 1.4\% patients. Superior division supplied segment VII and VIII and inferior division supplied segment V and VI.

As this study was conducted on a large number of patients $(\mathrm{n}=500)$ and both axial as well as 3dimensional images were evaluated on an advanced CT work station, the results of our study therefore may reflect the prevalence of portal vein anatomy more accurately. However, there are some limitations of our study as well. Our study was confined to the detailed assessment of MPV and RPV anatomy only. Variations in hepatic arterial anatomy, LPV, hepatic venous and biliary anatomy are also equally important from presurgical assessment point of view. In order to reduce the complexity, we confined our study to the main portal vein and right portal vein anatomy only. Classifying the prevalence of MPV branching as either extrahepatic or intrahepatic is also very important for hepatic transplantation, which was not done in our study. ${ }^{16}$

Even normal branching anatomy does not ensure secure transplantation as intrahepatic branching of MPV is a contraindication for liver transplantation. ${ }^{17}$ Besides knowing the variation pattern, the diameter of each of the branch of portal vein also needs to be assessed during pre-transplant evaluation. ${ }^{18}$

\section{Conclusion}

In conclusion, variations are easily detected by the recent MDCT scanners in both right and main portal vein anatomy. Also the 3-dimensional applications of MDCT like volume rendering and MIP further enhance the ability of radiologist to accurately report these variations. Z-type pattern is the most common variation in MPV branching. Variant anatomy of right portal vein is as common as MPV. We also found new branching variation of RPV bifurcating into superior and inferior division which has not been described previously.

\section{References}

1. Sharafuddin MJ, Wroblicka JT, Sun S, Essig M, Schoenberg SO, Yuh WT. Percutaneous vascular intervention based on gadolinium-enhanced MR angiography. J VascIntervRadiol. 2000;11(6):739-46.

2. Kamel IR, Kruskal JB, Pomfret EA, Keogan MT, Warmbrand G, Raptopoulos V. Impact of multidetector $\mathrm{CT}$ on donor selection and surgical planning before living adult right lobe liver transplantation. AJR Am J Roentgenol. 2001;176(1):193-200.

3. Kamel IR, Raptopoulos V,Pomfret EA, et al. Living adult right lobe liver transplantation: imaging before surgery with multidetector multiphase CT. AJR Am J Roentgenol. 2000;175(4):1141-3.

4. Akgul E, Inal M, Soyupak S, Binokay F, Aksungur E, Oguz M. Portal venous variations. Prevalence with contrast-enhanced helical CT. ActaRadiol. 2002;43(3):315-9.

5. Atasoy C, Ozyürek E. Prevalence and types of main and right portal vein branching variations on MDCT. AJR Am J Roentgenol. 2006;187(3):676-81.

6. Covey AM, Brody LA, Getrajdman GI, Sofocleous CT, Brown KT. Incidence, patterns, and clinical relevance of variant portal vein anatomy. AJR Am J Roentgenol. 2004;183(4):1055-64.

7. Kishi Y, Sugawara Y, Kaneko J, Matsui Y, Akamatsu N, Makuuchi M. Classification of portal vein anatomy for partial liver transplantation. Transplant Proc. 2004;36(10):3075-6.

8. Marcos A, Ham JM, Fisher RA, Olzinski AT, Posner MP. Surgical management of anatomical variations of the right lobe in living donor liver transplantation. Ann Surg. 2000;231(6):824-31.

9. Marcos A, Orloff M, Mieles L, Olzinski A, Sitzmann J. Reconstruction of double hepatic arterial and portal venous branches for right-lobe living donor liver transplantation. Liver Transpl. 2001;7(8):673-9.

10. Hwang S, Lee SG, Lee YJ, et al. Donor selection for procurement of right posterior segment graft in living donor liver transplantation. Liver Transpl. 2004;10(9):1150-5.

11. Sureka B, Patidar Y, Bansal K, Rajesh S, Agrawal N, Arora A. Portal vein variations in 1000 patients: surgical and radiological importance. Br J Radiol 2015;88:20150326.

12. Varotti G, Gondolesi GE, Goldman J, et al. Anatomic variations in right liver living donors. J Am Coll Surg. 2004;198(4):577-82.

13. Baba Y, Hokotate H, Nishi H, Inoue H, Nakajo M. Intrahepatic portal venous variations: demonstration by helical CT during arterial portography. J Comput Assist Tomogr. 2000;24(5):802-8.

14. Guiney MJ, Kruskal JB, Sosna J, Hanto DW, Goldberg SN, Raptopoulos V. Multi-detector row CT of relevant vascular anatomy of the surgical plane in split-liver transplantation. Radiology. 2003;229(2):401-7.

15. Soyer P, Bluemke DA, Choti MA, Fishman EK. Variations in the intrahepatic portions of the hepatic and portal veins: findings on helical CT scans during arterial portography. AJR Am J Roentgenol. 1995;164(1):103-8. 
16. Fasel JH, Muster M, Gailloud P, Mentha G, Terrier F. Duplicated hepatic artery: radiologic and surgical implications. ActaAnat (Basel). 1996;157(2):164-8.

17. Chen YS, Cheng YF, De villa VH, et al. Evaluation of living liver donors. Transplantation. 2003;75(3 Suppl):S16-9.

18. Inomata Y, Uemoto S, Asonuma K, Egawa H. Right lobe graft in living donor liver transplantation.

Transplantation. 2000;69(2):258-64. 